\title{
ON THE FINANCIAL AND RISK ANALYSIS OF WASTE TREATMENT PROJECTS IN GREECE
}

\author{
A.C. KARMPERIS, I.P. TATSIOPOULOS, A. SOTIRCHOS \& K. ARAVOSSIS \\ Sector of Industrial Management and Operational Research, School of Mechanical Engineering, \\ National Technical University of Athens, Greece.
}

\begin{abstract}
Risk assessment is one of the most critical procedures for the evaluation of environmental projects. Over the last decades, there are several methods and techniques developed in the risk assessment literature establishing the quantitative risk analysis of waste treatment projects. Herein, the authors focus on the correlation between the financial sustainability evaluation and the quantitative risk analysis of waste treatment projects, which are implemented with Build-Operate-Transfer contracts in Greece. Particularly, the authors use a formula for the investor's profit rate computation, which corresponds in positive cash flows throughout the project's operational phase and ensures the partnership's financial sustainability. Documentation of the specific formula is achieved through the quantitative risk analysis of a waste treatment project, where the uncertainty of the project's financial sustainability is analyzed and useful conclusions are discussed.

Keywords: Build-Operate-Transfer, financial sustainability, Monte Carlo simulation, quantitative risk analysis, waste treatment projects.
\end{abstract}

\section{INTRODUCTION}

Over the past two decades, public private partnership (PPP) contracts are used by many governments for the purpose of delivering a project or a service that is traditionally provided by the public sector. Generally, these types of contracts include the collaboration between the public and the private sector, while in most cases the private partner is responsible for the project funding and the invested capital is recovered through the operation revenue over the concession period. According to the World Bank Group's database [1], for the period 1990-2009, there are 400 investments with private participation implemented in the waste treatment (WT) field. Since the PPP projects are becoming a popular option for the public services delivery, there are many authors who refer to specific large WT projects implemented in different countries [2-4], while other researchers focus on the identification and analysis of their key aspects [5]. These projects are mainly implemented following a Build-Operate-Transfer (BOT) contract, which is the most commonly used contract type in PPPs [6]. Generally, BOT contracts can be defined as long-term cooperation agreements for the provision of high quality infrastructure, products, or services [7], with which significant technical, legal, political, and economic risks are shared between the public and private sectors [8]. In a previous study, we examined the financial sustainability of the WT projects that were implemented through PPPs in Greece [9] and we developed a formula for the computation of the investor's profit rate (PR). The PR's minimum value that is calculated through the specific formula can be used by decision makers to achieve the positive cash flows on behalf of the private sector throughout the project's time horizon, ensuring the partnership's financial sustainability. Herein, we use the results arising through the above formula and we implement the quantitative risk analysis (QRA) of a WT project to validate the project's financial sustainability.

The rest of this paper is organized as follows. The framework of the BOT contracts is presented in Section 2 and the review of the literature on the commonly used methods for the financial analysis and the QRA are presented in Section 3. A QRA for the evaluation of a WT project is implemented in Section 4, while the results are discussed in Section 5 and useful conclusions are summarized in Section 6. 


\section{FRAMEWORK OF BOT CONTRACTS}

In 2006, due to the increased number of PPP projects in Europe, EU Committee issued the Green Bible on PPPs [10], which included 22 questions relevant to the issues of partnership contracts. This paper was sent to the EU's member states for collecting the appropriate data and establishing a common legislative framework for the implementation of PPP projects in Europe. In Greece, three large infrastructure projects, that is, the Rio - Antirio Bridge, the Attiki Odos Highway, and the International Airport of Athens [11], were already implemented following the BOT contracts, while the specific national legislative framework for PPPs was established in 2005 with the Law 3389. Currently, among the 52 PPP projects already approved by the Greek interministerial committee, there are two projects in the environmental sector that include the construction and operation of WT units in the region of Western Macedonia and the municipality of Rafina. However, implementation of WT projects requires complicated procedures $[12,13]$, especially when these projects follow BOT contracts [14]. Generally, a BOT contract should take into consideration all the project's parameters to ensure the value for money that is achieved through the project's operation $[15,16]$. Therefore, the literature includes several papers analyzing key factors for BOT projects [17] and particularly for environmental [18] as well as for WT projects $[19,20]$.

\section{FINANCIAL ANALYSIS AND QRA}

In the literature reviewed, there are several methods proposed for the investment assessment, while the WT projects are mainly evaluated through the multicriteria analysis [21], the life cycle assessment [22], and the cost-benefit analysis (CBA) [23]. However, the CBA is a widely used method, which can be used during the initial stage for the evaluation of the environmental impact [24] as well as for alternative types of WT projects [25] and particularly for projects that follow BOT contracts [26]. The formula for the computation of the investor's PR, which is used in this paper, has as theoretical foundation the CBA guide for investment projects issued by the European Commission (EC) [27]. A remarkable point is that the submission of a project proposal including a CBA is mandatory for all large projects (environmental projects with higher than 25 million Euros budget) in the 2007-2013 period, which has been cofinanced by the European Community. According to the EC's guide, the financial analysis and the risk assessment are two out of the six basic steps that should be followed in a project's appraisal through the CBA.

\subsection{Financial analysis and financial sustainability}

Generally, main purpose of the financial analysis for a project implemented through a BOT contract is to use the project cash flow forecasts to calculate the suitable net return indicators for the private sector through the annual payments by the public sector. The financial indicators, which are calculated in the financial analysis, are the net present value (NPV) and the internal rate of return (IRR) [28]. In BOT projects, the performance of the private capital is implemented through the calculation of the financial NPV of the private capital. In addition, the investment's profitability can also be measured by the profitability index (PI), which is calculated by the total inflows in present value (PV), divided by the total outflows in PV. In BOT projects, the PI corresponds to the net percentage profit for the private sector, as it takes into account all the net inflows divided by the relative outflows. These outflows are estimated with the sum of the initial investment for the infrastructure construction and the capital that will be invested annually for various reasons, such as the payment of the subcontracting agreements, or the loan repayments, etc. However, crucial in the financial analysis is the loan's interest rate as well as the inflation that is used to adjust cash flows in future value (FV), because both have an impact on the investor's annual net cash flows calculated through 
the inflows minus the relative outflows. Moreover, financial analysis includes the evaluation of the project's financial sustainability, which is a critical issue in all types of investment projects. It is mentioned that a project is classified as financially sustainable, when it does not incur the risk of running out of cash in the future. Therefore, the financial sustainability's criterion is the annual cash flows to be positive throughout the project's time horizon for the project's operator.

\subsection{Quantitative risk analysis}

QRA is the last step of the CBA and supports the total project's evaluation process, simply by weighing the performance with the incurred risk. In BOT projects, risk allocation is a critical success factor, while it is mentioned that the risks should be allocated to the sector that is best able to manage them [29]. Specifically, it is suggested that the private sector should take the majority of the responsibilities for the project level risks and specifically to take the design, construction, and operation risks. However, in all cases, a QRA is implemented through the calculation of the cumulative probability distribution functions of the main evaluation indicators, namely the NPV and the IRR. These functions are analyzed by decision makers to asses the project's risks during the feasibility stage [30]. For instance, as shown by $\mathrm{Ng}$ et al. [31], in case the probability for negative NPV is higher than a predefined level, then the examined scenario should be considered as risky and not be preferred, otherwise, it should be selected.

In the literature, several methods for the investment's QRA are suggested and some of the mostly used techniques are the sensitivity analysis and the Monte Carlo simulation [32-34]. In the sensitivity analysis, different values are given separately to the variables to estimate the impact that each variable has on the main evaluation indicators. Furthermore, the Monte Carlo simulation that is used in various types of uncertainty analysis [35-37] defines the potential range of the evaluation indicators' values graphically expressed as the evaluation indicators' cumulative probability distribution functions.

\section{CASE STUDY: QRA AND FINANCIAL SUSTAINABILITY ASSESSMENT OF A WT PROJECT IN GREECE}

In this section, we consider an investment in the WT field, which is implemented through a BOT contract and we examine its financial sustainability through the QRA. The project is located in Greece and includes the reuse of well-purified waste water for multiple purposes after an intensive tertiary treatment process. Particularly, the private participant is responsible for the construction of wastewater treatment facilities for a city of 200,000 residents in the first year and the operation of the assets for 20 years.

\subsection{Initial investment, cash inflows and outflows}

The initial investment cost for the construction of the WT facilities is estimated at $€ 48,000,000$, which does not include general costs or profits. This cost is funded by the private sector through a bank loan and is initially divided into annual equal flows throughout the project's operational phase, that is, $€ 2,400,000$ per year in PV. The annual operational cost for the first year of the operational phase is estimated at $€ 3,600,000$ in PV, in which no general costs or profits are included. These costs are considered as outflows for the private sector, while the annual payments from the public sector are considered as inflows. Furthermore, the maintenance cost for the first year is estimated at $0.4 \%$ of the initial investment cost, that is, $€ 220,000$ in PV. Other assumptions included in the financial analysis is the loan's fixed interest rate of $6.65 \%$, while the annual payments are also fixed and the loan's 


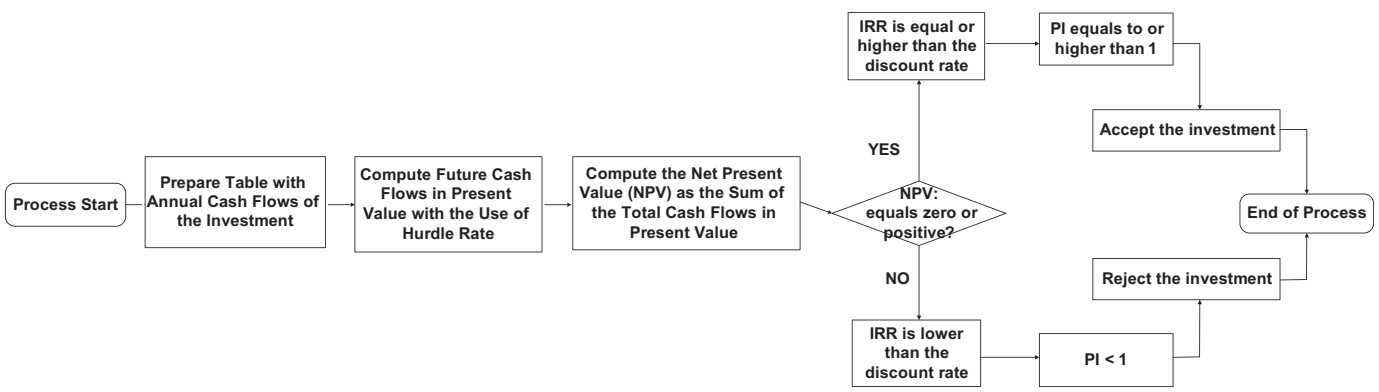

Figure 1: Process flowchart: investment assessment with the discounted cash flow analysis.

amortization period is equal to the project's operational phase, that is, 20 years. Furthermore, the discount rate that is used in the case study is $7.5 \%$, which is normal in the Greek PPP market.

\subsection{Financial indicators}

All data are adjusted in FV following the inflation, which is considered 3\%. In the financial analysis, the process flowchart for the calculation of the evaluation indicators, namely the NPV, the IRR, and the PI, is illustrated in Fig. 1. These indicators are calculated on behalf of the private sector, who is the operator of the investment, to evaluate the project's performance. Specifically, there are two options:

- If the NPV $\prec 0 \quad$ IRR $\prec$ discount rate PI $\prec 1$, then the project is unprofitable and should not be accepted by the private investor and

- If the NPV $\geq 0 \quad$ IRR $\geq$ discount rate PI $\geq 1$, then the project should be accepted.

\subsection{Consideration of financial scenarios for different values of the PR}

To estimate the annual payments by the public sector, there are two scenarios examined, where the initially estimated costs are increased by $18 \%$ and $28 \%$, respectively, according to the PR designated by the legislation of public construction projects in Greece. These ratios are used in the project's budget estimation process to increase the costs arising through the tariffs specified by the Ministry of Public Works, which contain specific articles for materials and works. Indicatively, the costs of construction, electromechanical, and other works are summarized and increased by specific PRs, that is, $18 \%$ for projects financed by the public investment program and $28 \%$ in other cases [38]. In the present case study, the diagrams of the cash flows in FV for the scenarios of PR $=18 \%$ and PR $=28 \%$ are illustrated in Fig. 2, while the calculations of the NPV and the PI for these scenarios, are presented in Table 1.

The review of the diagrams in Fig. 2 focuses on the existence of a switching point, that is, the point where the total inflows are equal to the relative outflows and where there is a change in the project's financial liquidity. Moreover, it is mentioned that the PI and the PR take different values, due to the fact that the cash flows adjusted with the PR are counted in FV, while these cash flows are discounted in PV with the use of the discount rate in the calculation of the PI evaluation indicator. Therefore, it is expected that $\mathrm{PI} \prec 1+\mathrm{PR}$. As can be seen in Table 1 , there is NPV $\succ 0 \quad$ IRR $\succ$ discount rate $\quad \mathrm{PI} \succ 1$. However, even though the investment is profitable for the investor, both the examined scenarios, in which the annual payments are adjusted in the $\mathrm{PR}=18 \%$ and $\mathrm{PR}=28 \%$, are evaluated as financially 


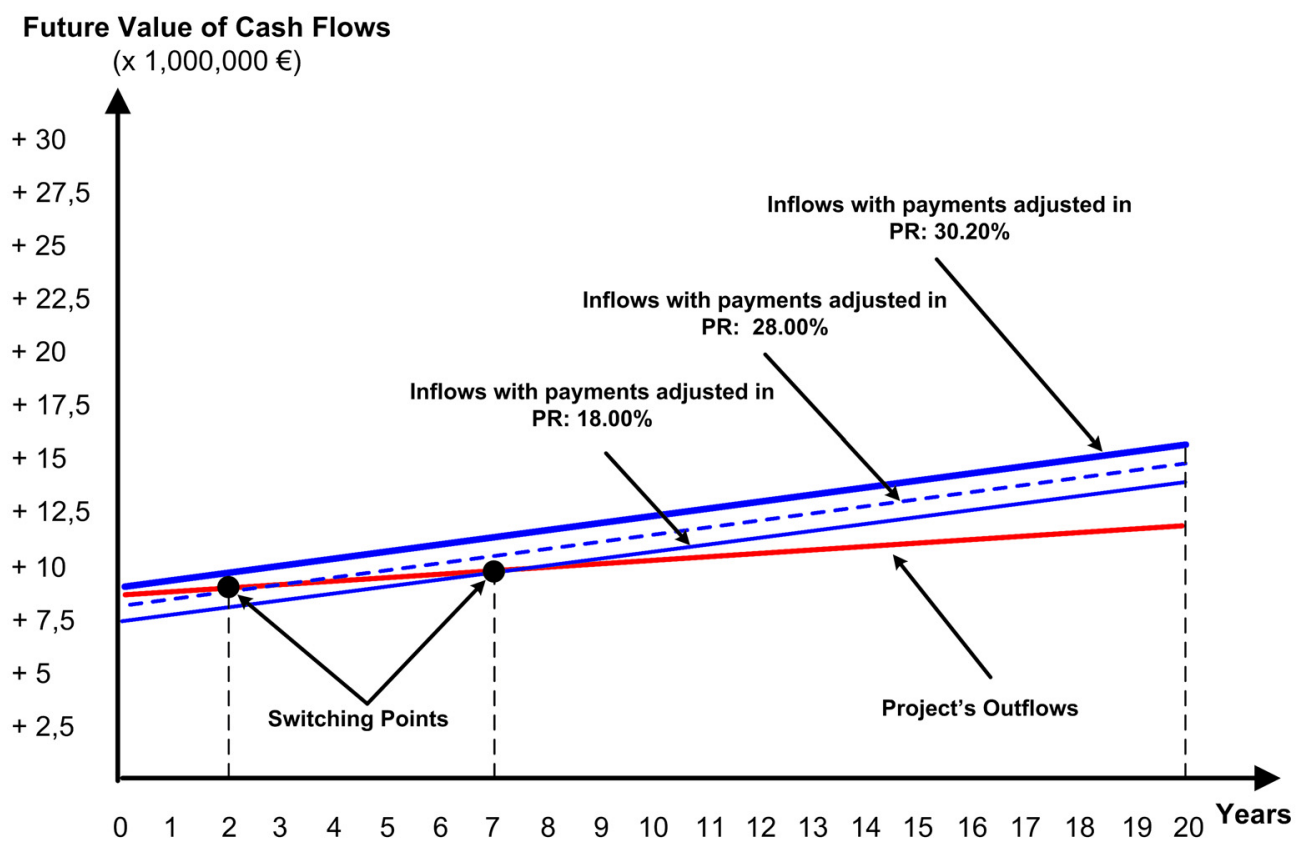

Figure 2: Cash flow diagrams for different PR scenarios (18\%; 28\%; and 30.20\%).

Table 1: Evaluation of the project's financial sustainability.

\begin{tabular}{lccccc}
\hline & & \multicolumn{3}{c}{ Financial Sustainability Assessment } \\
\cline { 4 - 6 } $\begin{array}{l}\text { Payments } \\
\text { adjusted at } \\
(\text { PR })(\%)\end{array}$ & $\begin{array}{c}\text { Profitability } \\
\text { index } \\
(\mathrm{PI})\end{array}$ & $\begin{array}{c}\text { Net present } \\
\text { value } \\
(\mathrm{NPV})\end{array}$ & $\begin{array}{c}\text { Lack of } \\
\text { liquidity } \\
\text { (years) }\end{array}$ & $\begin{array}{c}\text { Switching point } \\
\text { (start of year) }\end{array}$ & $\begin{array}{c}\text { Availability } \\
\text { capital } \\
\text { (year) }\end{array}$ \\
\hline 18 & $1.01417>1$ & $+1,350,000$ & $0-7$ & 8th year & $8-20$ \\
28 & $1.10012>1$ & $+9,530,000$ & $0-2$ & 3rd year & $3-20$ \\
30.20 & $1.11903>1$ & $+11,330,000$ & - & - & $0-20$ \\
\hline
\end{tabular}

unsustainable. This is demonstrated according to the diagrams illustrated in Fig. 2, where there is a lack of liquidity for the first 2 and 7 years of the operational phase, respectively.

Furthermore, we use the following Formula (1), which is developed by Sotirchos et al. [9]:

$$
P R \geq \frac{c \times(1+r)+\frac{a}{\sum_{1}^{n} \frac{1}{(1+p)^{n}}}}{\left(\frac{a}{v}+c\right) \times(1+r)}-1,
$$

where: $a=$ capital funded through loan, $v=$ operational phase (in years), $c=$ annual operating costs, $r=$ interest rate (inflation), $p=$ loan's interest rate (fixed), and $n=$ loan's amortization period (in years). 
According to the values used in the case study, that is, $a=€ 48,000,000.00 ; v=20.00 ; c=€$ $3,820,000.00 ; r=3.00 \% ; p=6.65 \%$; and $n=20.00$, Formula (1) gives PR $\geq 30.20 \%$.

The $30.20 \%$ is the PR's minimum value to achieve positive cash flows throughout the project's operational phase, ensuring the partnership's financial sustainability. Particularly, with the use of this value for the adjustment of the annual payments by the public sector, the results presented in Table 1 and Fig. 2, demonstrate that the specific scenario is financially sustainable.

However, the main limitation in the above calculations is that variables get only their most probable values and no forecasts are considered regarding their variations. That is, in the following subsection we implement the QRA for the specific WT project to study the probability of the project's financial sustainability as well as its performance on behalf of the private investor.

\subsection{Quantitative risk analysis}

Initially, we use Formula (1) to implement the sensitivity analysis of the PR's minimum value. Specifically, the base case values of the variables: capital funded through loan; operational phase (in years); annual operating costs; inflation; loan's interest rate, are increased and decreased by $15 \%$ and we examine the impact that these variations have on the PR's minimum value. The results are illustrated in Fig. 3. As can be seen, the project's operational phase has greater impact on the PR's value, which is initially estimated at $30.20 \%$, because a change of $\pm 15 \%$ in the variable's value that is 20 years, that is, 17 and 23 years respectively, has a total variation of $15.2241 \%$, that is, it minimizes and maximizes the PR's minimum value from $21.9216 \%$ to $37.1457 \%$. Further, while the impact of the loan's interest rate is $10.8220 \%$, the relative impact of the operational cost is $5.5983 \%$, and the impact of the initial investment and the inflation are counted at $5.5744 \%$ and $0.609 \%$, respectively.

\section{Sensitivity Tornado Graph}

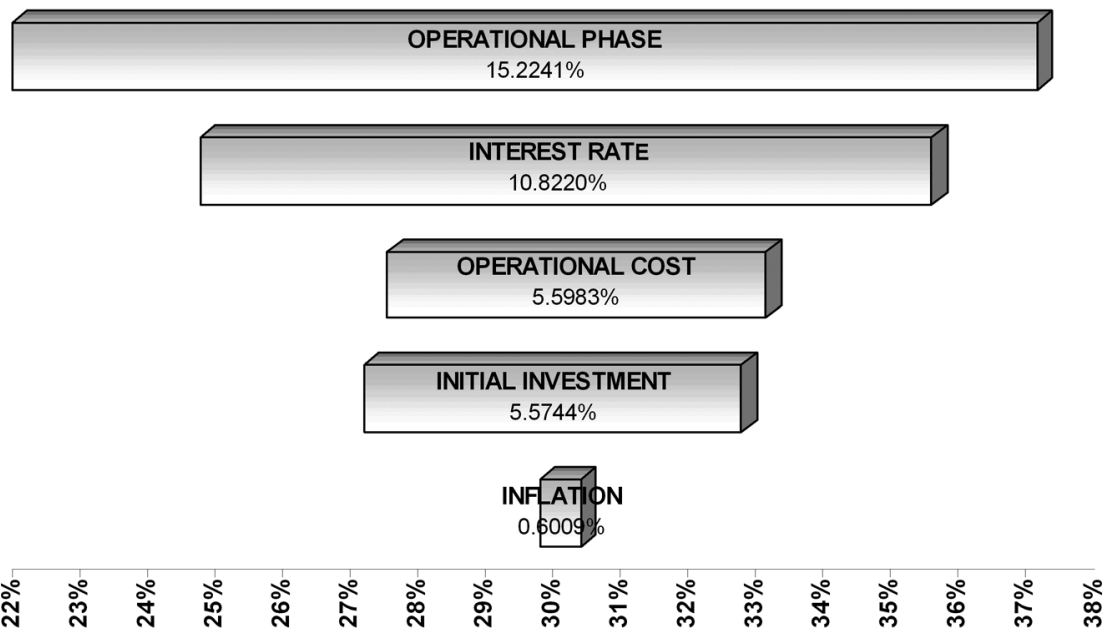

Profit Rate's minimum value

Figure 3: Sensitivity analysis of the PR's minimum value. 
Table 2: Probability distribution of the project's variables.

\begin{tabular}{lccccc}
\hline & & Probability & \multicolumn{2}{c}{ Minimum } & Base case \\
Variables & Units & distributions & value & value & value \\
\hline Operational phase & $($ Years $)$ & Triangular & 17 & 20 & 23 \\
Loan's interest rate & $(\%)$ & Normal & \multicolumn{4}{c}{$\mu=6.65 \%, \sigma=0.15$} \\
Operational cost & $(€)$ & Triangular & 350,000 & 382,000 & 450,000 \\
Initial investment & $(\times 1,000)$ & Triangular & 42,000 & 48,000 & 58,000 \\
& $(€)$ & & & & \\
Inflation & $(\%)$ & PERT & 1.50 & 3.00 & 5.50 \\
\hline
\end{tabular}

These results give rise to the concept that Monte Carlo simulation should be used for a more detailed approximation of the potential result. We mention that a variable's impact on the PR's minimum value is calculated when the other variables retain their base case values. Thus, there are different probability distribution functions assigned to each one of the variables in Formula (1) to develop a Monte Carlo simulation model and to calculate the overall impact of the variables on the project's performance. These distributions are presented in Table 2.

Furthermore, a Monte Carlo simulation model is developed where the variables illustrated in Table 2 are defined as inputs while the private sector's NPV is defined as output, respectively. Moreover, there are three different PR scenarios, which are evaluated according to the Monte Carlo simulation model. These are the $\mathrm{PR}=18 \%, \mathrm{PR}=28 \%$, and $\mathrm{PR}=30.2 \%$, which result in the $\mathrm{NPV}_{(18 \%)}$, $\mathrm{NPV}_{(28 \%)}$, and $\mathrm{NPV}_{(30.2 \%)}$, respectively. The simulation is performed with 5,000 runs using random quantities of the defined inputs [39,40], so that the overall impact of the project's variables is taken into account and the possible range of the $\mathrm{NPV}_{(18 \%)}, \mathrm{NPV}_{(28 \%)}$, and $\mathrm{NPV}_{(30.2 \%)}$ evaluation indicators is calculated, graphically expressed as the cumulative probability distribution functions. These functions are illustrated in Fig. 4.

Through the simulation, the evaluation indicator's expected value for each PR scenario is estimated, which is defined as the sum of all possible values of the NPV where each value multiplied by its probability of occurrence. As can be seen in Fig. 4, the expected value of the $\mathrm{NPV}_{(18 \%)}=-66,244 €$, while the relative expected values of the other PR scenarios are estimated: $\mathrm{NPV}_{(28 \%)}=7,679,055 €$ and $\mathrm{NPV}_{(30.2 \%)}=9,514,183 €$. This means that the first scenario, where the annual payments by the public sector are increased at the PR of $18 \%$, is expected to be unprofitable for the private sector. Furthermore, we analyze the resulting cumulative probability distribution functions of the evaluation indicators in two specific NPV values, which are the NPV $=0$ and NPV $=10,000,000$. Specifically, we estimate the probability of the examined scenarios' NPVs to get higher than these values. The results are illustrated in Table 3.

As can be seen in Table 3, for the first PR scenario, where the annual payments by the public sector are adjusted at the $\mathrm{PR}=18 \%$, there is $48.28 \%$ probability for the $\mathrm{NPV}_{(18 \%)}$ to be positive, that is, there is $(100-48.28) \%=51.72 \%$ to be negative. Moreover, for the second and third scenarios, where the annual payments are adjusted at the $\mathrm{PR}=28 \%$ and $\mathrm{PR}=30.2 \%$, respectively, the probability for the $\mathrm{NPV}(28 \%) \geq 0$ is estimated at $83.86 \%$ and the relative probability for the $\operatorname{NPV}(30.2 \%) \geq 0$ is estimated at $88.90 \%$. These results demonstrate that the probability of the investment to be unprofitable is $(100-83.86) \%=16.14 \%$ and $(100-88.90) \%=11.10 \%$, for the second and third scenarios, respectively. 


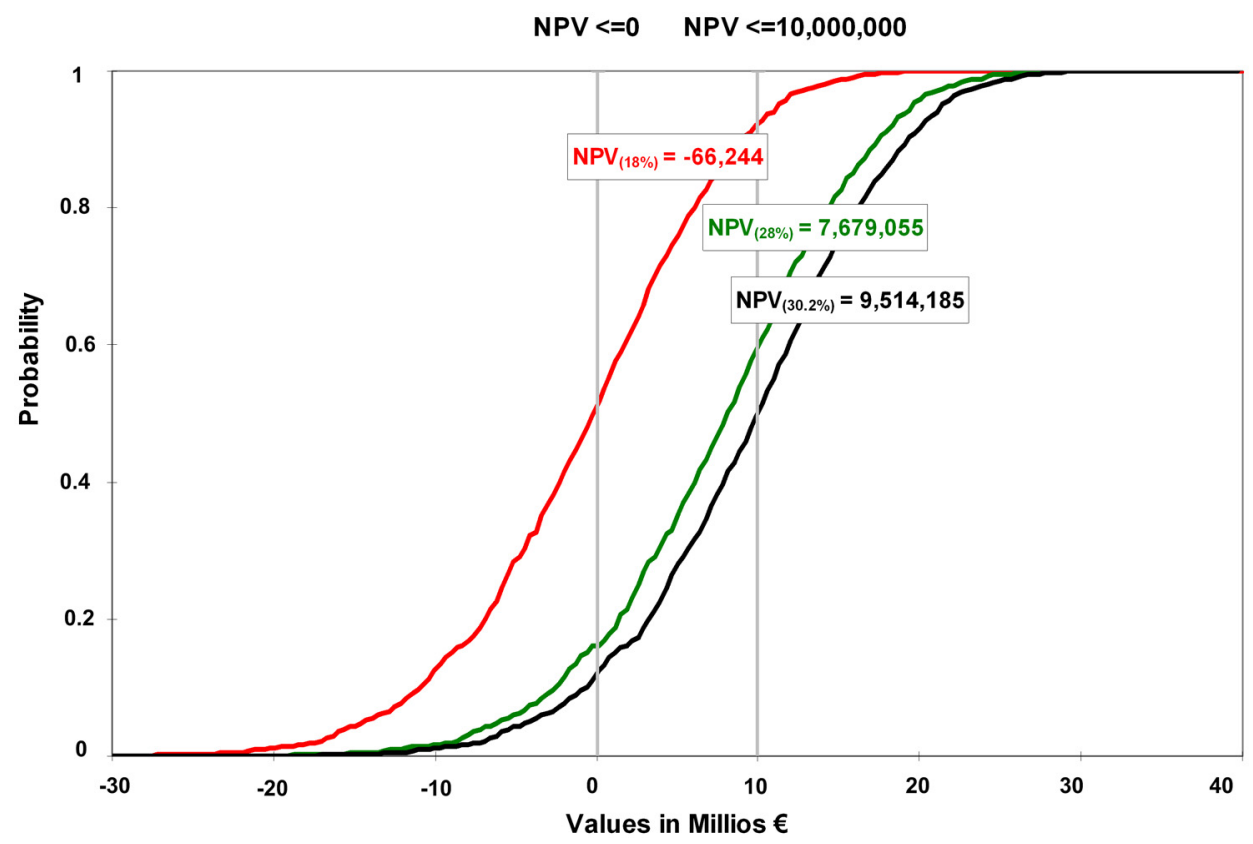

Figure 4: Cumulative probability distribution functions for different PR scenarios.

Table 3: Analysis of the cumulative probability distribution functions.

\begin{tabular}{lccc}
\hline \multirow{2}{*}{$\begin{array}{l}\text { Payments adjusted at } \\
\text { the PR }\end{array}$} & \multicolumn{2}{c}{ Probability of } \\
\cline { 3 - 4 } & NPV's expected value & $\mathrm{NPV} \geq 0(\%)$ & $\mathrm{NPV} \geq 10,000,000(\%)$ \\
\hline 18 & $-662,443.5$ & 48.28 & 8.06 \\
28 & $+7,679,055.0$ & 83.86 & 39.69 \\
30.20 & $+9,514,185.0$ & 88.90 & 49.001 \\
\hline
\end{tabular}

Therefore, according to the results presented in Table 3, we conclude that the use of Formula (1), not only ensures the partnership's financial sustainability, but also has a positive impact on the project's performance, as the probability of the is increased or the relative probability of the is decreased.

\section{DISCUSSION}

The incurred conclusion is that in the WT projects implemented through BOT contracts in Greece, where the bank loan's interest rate is fixed and the annual payments are equal, it is inefficient to follow the conventional public procurement process to estimate the project's budget, that is, to increase the estimated costs with a PR of $18 \%$ or $28 \%$. Therefore, Formula (1) that is developed by Sotirchos et al. [9], can be a useful tool to public decision makers, as it computes the PR's minimum value to achieve positive cash flows throughout the project's operational phase and to ensure the partnership's financial sustainability. However, the specific formula can be used similarly in other investment 
types, for example, in cooperative agreements among two or more partners [41] or for the calculation of the appropriate PR in selling products.

Herein, we examine the results arising through this formula to demonstrate that there is also a positive impact on the project's performance. Particularly, we use a basic method for the investment assessment that is the discounted cash flow analysis, where the main evaluation indicators used is the NPV, the IRR, and the PI. A specific case study is presented, where a WT project implemented in Greece through a BOT contract is examined. Initially, the project's financial analysis is implemented, where the scenarios for the payments by the public sector are adjusted in the PR of $18 \%$ and $28 \%$, as obliged by the Greek law on conventional public projects procurement, but are evaluated as financially unsustainable. Furthermore, we use the variables included in the specific formula and implement the QRA for the above scenarios $(\mathrm{PR}=18 \%$ and $\mathrm{PR}=28 \%)$ as well as the scenario calculated through the formula ( $\mathrm{PR}=302.2 \%$ ). In the QRA, the sensitivity analysis of the project's variables is implemented, where the project's variables are classified according to their impact on the project's performance. In addition, specific probability distributions are assigned to these variables and a Monte Carlo simulation model is developed, where the variables are defined as inputs and the NPV evaluation indicator is defined as output. The Monte Carlo simulation is performed once for the three PR scenarios and the resulting cumulative probability distribution functions of the $\mathrm{NPV}_{(18 \%)}$, $\mathrm{NPV}_{(28 \%)}$, and $\mathrm{NPV}_{(30.2 \%)}$ are further analyzed.

\section{CONCLUSIONS}

This research, having as a strong theoretical foundation of the QRA approach, as presented in the EC's guide to CBA for investment projects, examines a formula for the computation of the investor's PR in WT projects that follow BOT contracts in Greece. The examined formula calculates the PR's minimum value, which results in positive cash flows throughout the project's operational phase, ensuring the partnership's financial sustainability. A QRA is implemented, which includes the sensitivity analysis of the formula's variables and the Monte Carlo simulation of three different PR scenarios. Through the QRA, it is concluded that the examined formula ensures the partnership's financial sustainability and increases the probability of the project to be profitable for the investor. Conclusively, the specific formula as well as the method that is used for the QRA can be very useful to the investment analysts, as it helps them to estimate with accuracy the WT project's initial budget and to evaluate alternative PR scenarios.

\section{REFERENCES}

[1] World Bank Group, PPP in Developing Countries, 2009 data results from the PPI Project Database, The World Bank Group, Public Private Infrastructure Advisory Facility, http://ppi. worldbank.org/explore/ppi_exploreSector.aspx?sectorID=4

[2] Grimsey, D. \& Lewis, M.K., Public Private Partnerships, the Worldwide Revolution in Infrastructure Provision and Project Finance (Chapter 1). The Nature of Partnerships, Edward Elgar: Cheltenham, pp. 5-9, 2007.

[3] Panggabean, A.T.P., Expanding Access to Basic Services in Asia and the Pacific Region: Public-Private Partnerships for Poverty Reduction, Asian and Development Bank, ERD Working Paper, No 87, pp. 1, 7, 14, 2006.

[4] Haarmayer, D. \& Mody, A., Financing Water and Sanitation Projects-The Unique Risks, The World Bank Group, Finance, Private Sector and Infrastructure Network, 151, pp. 1-4, 1998.

[5] Tang, L., Shen, Q. \& Cheng, E.W.L., A review of studies on Public-Private Partnership projects in the construction industry, International Journal of Project Management, 28(7), pp. 683-694. doi: http://dx.doi.org/10.1016/j.ijproman.2009.11.009 
[6] Zhang, X-q. \& Kumaraswamy, M.M., Hong Kong experience in managing BOT projects, Journal of Construction Engineering and Management, 127(2), pp. 154-162, 2001. doi: http:// dx.doi.org/10.1061/(ASCE)0733-9364(2001)127:2(154)

[7] Karmperis, A.C., Sotirchos, A., Aravossis, K. \& Tatsiopoulos, I., Funding evaluation model for the implementation of wastewater treatment projects through Public Private Partnerships. Environmental Economics and Investment Assessment III, WIT Transactions on Ecology and the Environment, 131, eds K. Aravossis \& C.A. Brebbia, WIT Press: Southampton, pp. 147-160, 2010.

[8] Maskin, E. \& Tirole, J., Public-private partnerships and government spending limits, International Journal of Industrial Organization, 26(2), pp. 412-420, 2008. doi: http://dx.doi. org/10.1016/j.ijindorg.2007.05.004

[9] Sotirchos, A., Karmperis, A.C., Aravossis, K. \& Tatsiopoulos, I., Financial sustainability of the waste treatment projects that follow PPP contracts in Greece: a formula for the calculation of the profit rate. Ecosystems and Sustainable Development VIII, WIT Transactions on Ecology and the Environment, 144, eds Y. Villacampa \& C.A. Brebbia, WIT Press: Southampton, pp. 285-299, 2011.

[10] European Union Committee, Green Bible for Public Private Partnerships. Brussels, 2004.

[11] Roumboutsos, A. \& Anagnostopoulos, K.P., Public-private partnership projects in Greece: risk ranking and preferred risk allocation, Construction Management \& Economics, 26(7), pp. 751-763, 2008. doi: http://dx.doi.org/10.1080/01446190802140086

[12] Linke, P. \& Kokossis, A., Advanced process systems design technology for pollution prevention and waste treatment, Advances in Environmental Research, 8(2), pp. 229-245, 2004. doi: http://dx.doi.org/10.1016/S1093-0191(02)00133-8

[13] Seadon, J.K., Integrated waste management-Looking beyond the solid waste horizon, Waste Management, 26(12), pp. 1327-1336, 2006.

[14] Martimort, D. \& Pouyet, J., To build or not to build: Normative and positive theories of public-private partnerships, International Journal of Industrial Organization, 26(2), pp. 393-411, 2008. doi: http://dx.doi.org/10.1016/j.ijindorg.2006.10.004

[15] Nisar, T.M., Value for money drivers in public private partnership schemes, International Journal of Public Sector Management, 20(2), pp. 147-156, 2007. doi: http://dx.doi. org/10.1108/09513550710731508

[16] Grimsey, D. \& Lewis, M.K., Are Public Private Partnerships value for money? Evaluating alternative approaches and comparing academic and practitioner views, Accounting Forum, 29(4), pp. 345-378, 2005. doi: http://dx.doi.org/10.1016/j.accfor.2005.01.001

[17] Zhang, X., Public Clients' Best Value Perspectives of Public Private Partnerships in Infrastructure Development, Journal of Construction Engineering and Management, 132(2), pp. 107-1-4, 2006.

[18] Geng, Y. \& Doberstein, B., Greening government procurement in developing countries: Building capacity in China, Journal of Environmental Management, 88(4), pp. 932-938, 2008. doi: http://dx.doi.org/10.1016/j.jenvman.2007.04.016

[19] Lozier, J.C., Smith, G., Chapman, J.W. \& Gattis, D.E., Selection, design, and procurement of a demineralization system for a surface water treatment plant, Desalination, 88(1-3), pp. 3-31, 1992. doi: http://dx.doi.org/10.1016/0011-9164(92)80103-G

[20] Francis Rillaerts, F., Concessions in the water sector, Desalination, 124(1-3), pp. 13-17, 1999. doi: http://dx.doi.org/10.1016/S0011-9164(99)00084-3

[21] Effat, H.A. \& Hegazy, M.N., Cartographic modeling of land suitability for industrial development in the Egyptian desert, International Journal of Sustainable Development and Planning, 5(1), pp.1-12, 2010. doi: http://dx.doi.org/10.2495/SDP-V5-N1-1-12 
[22] Çelik, B., Girgin, S., Yazici, A. \& Ünlü, K.A., Decision support system for assessing landfill performance, Waste Management, 30(1), pp. 72-81, 2010. doi: http://dx.doi.org/10.1016/j. wasman.2009.09.016

[23] Aravossis, K. \& Karydis, V., Combination of monetary valuation techniques and application to environmental impact receptors, Fresenius Environmental Bulletin, 13(3b), pp. 283-288, 2004.

[24] Sfakianaki, E., \& Stovin, V.R., A spatial framework for environmental impact assessment and route optimisation, Proceedings of the Institution of Civil Engineers: Transport, 153(1), pp. 43-52, 2002.

[25] Lavee, D., A cost-benefit analysis of a deposit-refund program for beverage containers in Israel, Waste Management, 30(2), pp. 338-345, 2010. doi: http://dx.doi.org/10.1016/j.wasman.2009.09.026

[26] UNECE, Guidebook on Promoting Good Governance in Public Private Partnerships. United Nations Economic Commission for Europe: Geneva, pp. 60-61, 2008. doi: http://dx.doi. org/10.1016/S1570-6672(09)60063-5

[27] European Commission, Guide to Cost - Benefit Analysis of Investment Projects, Directorate General Regional Policy, Brussels, 2008.

[28] Kepaptsoglou, K., Karlaftis, M.G. \& Li, Z., Optimizing Pricing Policies in Park-and-Ride Facilities: A Model and Decision Support System with Application, Journal of Transportation Systems Engineering and Information Technology, 10(5), pp. 53-65, 2010.

[29] European Commission, Resource Book on PPP Case Studies. Directorate General Regional Policy, Brussels, pp. 9, 2004.

[30] Chou, J-S, Yang, I-T. \& Chong, W.K., Probabilistic simulation for developing likelihood distribution of engineering project cost. Automation in Construction, 18(5), pp. 570-577, 2009. doi: http://dx.doi.org/10.1016/j.autcon.2008.12.001

[31] Ng, S.T., Xie, J., Skitmore, M. \& Cheung, Y.K., A fuzzy simulation model for evaluating the concession items of public-private partnership schemes, Automation in Construction, 17(1), pp. 22-29, 2007.

[32] Rentizelas, A., Tziralis G. \& Kirytopoulos, K., Incorporating uncertainty in optimal investment decisions, World Review of Entrepreneurship, Management and Sustainable Development, 3(3/4), pp. 273-283, 2007. doi: http://dx.doi.org/10.1504/WREMSD.2007.014046

[33] Karmperis, A.C., Sotirchos, A., Aravossis, K., \& Tatsiopoulos, I.P., Waste management project's alternatives: A risk-based multi-criteria assessment (RBMCA) approach, Waste Management, 32(1), pp. 193-211, 2012.

[34] Diamantas, V., Kirytopoulos, K., \& Leopoulos, V., Project's duration prediction: traditional tools or simulation? World Review of Entrepreneurship, Management and Sustainable Development, 3(3/4), pp. 317-333, 2007. doi: http://dx.doi.org/10.1504/WREMSD.2007.014049

[35] Lagaros, N.D., Multicomponent incremental dynamic analysis considering variable incident angle, Journal of Structure and Infrastructure Engineering, 6(1-2), pp. 77-94, 2010. doi: http://dx.doi.org/10.1080/15732470802663805

[36] Mitropoulou, Ch.Ch., Lagaros, N.D., \& Papadrakakis, M., Life-cycle cost assessment of optimally designed reinforced concrete buildings under seismic actions, Reliability Engineering and System Safety, 96(10), pp. 1311-1331, 2011. doi: http://dx.doi.org/10.1016/j. ress.2011.04.002

[37] Lagaros, N.D., Probabilistic fragility analysis of RC buildings designed with different rules, Journal of Earthquake Engineering and Engineering Vibration, 7(1), pp. 45-56, 2008. doi: http://dx.doi.org/10.1007/s11803-008-0823-x 
[38] National Law. No 3669: Ratification of the Codification of Public Works Legislation. Gov. 116, June 18, 2005: Article 17: Contractual Issues, contained in Article 5 of Decree 609/85; 2008. (in Greek)

[39] Rezaie, K., Amalnik, M.S., Gereie, A., Ostadi, B. \& Shakhseniaee, M., Using extended Monte Carlo simulation method for the improvement of risk management: Consideration of relationships between uncertainties, Applied Mathematics and Computation, 190(2), pp. 1492-1501, 2007. doi: http://dx.doi.org/10.1016/j.amc.2007.02.038

[40] Tziralis, G., Kirytopoulos, K., Rentizelas, A. \& Tatsiopoulos, I., Holistic Investment Assessment: Optimization, Risk Appraisal and Decision Making, Managerial and Decision Economics, 30(6), pp. 393-403, 2009. doi: http://dx.doi.org/10.1002/mde.1458

[41] Karmperis, A.C., Sotirchos, A., Aravossis, K., \& Tatsiopoulos, I.P., A cooperative game theory approach for the equal profit and risk sharing, Proc. of the 2nd European Conference of Systems (ECS'11), Puerto De La Cruz, Tenerife, Spain, December 10-12, 2011. 